\title{
Quantification and Distribution of the 16SrIV-D Phytoplasma in the Wild Date Palm, Phoenix sylvestris, at Different Stages of Decline Using Quantitative PCR (qPCR) Analysis
}

\author{
Brian W. Bahder, ${ }^{\dagger}$ Noemi Soto, De-Fen Mou, Alessandra R. Humphries, and Ericka E. Helmick \\ Department of Entomology and Nematology, University of Florida-Fort Lauderdale Research and Education Center, Davie, FL \\ 33314-7719
}

\begin{abstract}
Lethal bronzing disease (LBD) is a fatal infection in a variety of ornamental palms in Florida caused by the 16SrIV-D phytoplasma. The disease was first found in 2006 in Florida and has since spread to 31 different counties, reaching as far north as Jacksonville and as far south as Key Largo. Stakeholders (nursery personnel, landscaping personnel, and extension agents) from across the state take and send samples for analysis. To provide better sampling recommendations and reduce the time associated with the sampling process, the distribution of the 16SrIV-D phytoplasma was examined by quantitative PCR analysis in various Phoenix sylvestris that displayed different stages of decline, including

The findings of this study revealed that regardless of the stage of decline, the highest amount of phytoplasma detected was nearest to the base of the trunk and gradually decreased further up the trunk. Also, in $P$. sylvestris it was found that with symptoms present, the entire trunk has a systemic infection, resulting in positive reactions for every sample taken. These data are useful to stakeholders because they provide useful sampling recommendations in that only a single sample is needed when sampling a palm suspected to be infected with phytoplasma. Also, based on these results, sampling lower on the trunk is advised.
\end{abstract} early symptoms, moderate symptoms, and late symptoms. A declining Sabal palmetto was also available for analysis and examined as well.

Keywords: Florida, lethal bronzing disease, palm, phytoplasma, qPCR

The 16SrIV-D phytoplasma is the causal agent of lethal bronzing disease (LBD) in Florida (Bahder and Helmick 2019). Symptoms of LBD include necrosis of inflorescence, premature fruit drop, "bronzing" of the older leaves that progress to younger leaves over time, and finally spear leaf collapse. The bronze coloration observed in symptomatic leaves varies between palm species infected but is distinct from the color of naturally senescing leaves (Bahder et al. 2019b). This pathogen was introduced into the western part of Florida sometime around 2006 or earlier and was first detected in Syagrus romanzoffiana, Phoenix canariensis, Phoenix sylvestris, and P. dactylifera (Harrison et al. 2008). The LBD phytoplasma belongs to the palm lethal decline 16S taxonomic group 16SrIV. Previously in Florida, 'Candidatus Phytoplasma palmae,' the causal agent of lethal yellowing (LY), was the only documented 16 SrIV phytoplasma in the state (Harrison et al. 1992).

Since its introduction, the disease has spread to 32 different counties, extending as far north as Jacksonville to the Florida Keys (Bahder and Helmick 2019). In addition to Florida, LBD was reported in Texas (Harrison et al. 2002), Louisiana (Singh and Ferguson 2017), and Mexico (Vázquez-Euán et al. 2011). In Florida, LBD has been implicated in the decline of 12 different species of palm that include Adonidia merrillii, Butia capitata, Carpentaria acuminata, Cocos nucifera, Livistona chinensis (Bahder et al. 2019a), Bismarckia nobilis (Dey et al. 2018), Phoenix canariensis, P. dactylifera, P. sylvestris, Syagrus romanzoffiana (Harrison et al. 2008), Sabal palmetto

${ }^{\dagger}$ Corresponding author: B. W. Bahder; bbahder@ufl.edu

Funding: Funding for this project was provided through the Animal and Plant Health Inspection Service Farm Bill cooperative agreement number 81300148-CA.

The author(s) declare no conflict of interest.

Accepted for publication 27 December 2019.

(C) 2020 The American Phytopathological Society
(Harrison et al. 2009), and Phoenix roebelenii (Jeyaprakash et al. 2011). Of these species, $P$. sylvestris is the most commonly infected (Bahder et al. 2019a). Although the most recent analysis documented palms as having a $\$ 404$ million impact on the green industry economy in Florida (Khachatryan and Hodges 2014), the true value has increased in recent years, and with an increase in the economic value, the economic loss associated with LBD is also increasing. An example is with one nursery reporting a loss of approximately $\$ 4$ million in a single plot of $P$. sylvestris (anonymous nursery, personal communication).

Sampling of infected palms or palms to verify whether they are healthy is accomplished by taking a tissue sample from the trunk of the palm (Bahder and Helmick 2018). Generally, stakeholders have been instructed to take multiple samples of palm trunk tissue at different heights and different locations around the circumference of the trunk because of a presumed low level of phytoplasma and uneven distribution in the palm. This protocol for sampling was used by Bahder et al. (2018a) and found high levels of phytoplasma in infected trunk tissue at different stages of decline. This study was conducted at the University of Florida-Fort Lauderdale Research and Education Center, where palm trees were easily accessible. However, the majority of samples taken by stakeholders are from an urban environment, increasingly along busy highways where many of the susceptible palm hosts are being planted and showing up infected. Therefore, reducing the sampling time per palm is desirable. Furthermore, taking multiple samples per palm is not ideal because it produces multiple holes in the trunk. Currently, stakeholders are instructed to take three to five samples per palm to test for phytoplasma. From an ornamental perspective this is not desirable because palms in Florida are purchased and planted for their appearance, and having multiple holes in the trunk can reduce the value of a given specimen. From a pathological perspective, generating multiple holes in a trunk can increase the likelihood of secondary infections establishing in the specimen. From a disease perspective as well as ornamental, creating fewer sampling holes in the palm is preferred.

The primary objective of this study was to map the distribution of the 16SrIV-D phytoplasma in the trunk of infected palms at different stages of decline. Knowing the distribution of phytoplasma in the trunk can help provide better sampling recommendations to 
stakeholders so that they can take fewer samples from a palm. The data obtained in this study were designed to be transferred to stakeholders so that they can reduce the amount of time and resources used on sampling a potentially infected palm while maintaining a high degree of confidence in the results of diagnostic tests and reducing the number of holes created in the palm trunk.

\section{Materials and Methods}

Sample identification, collection, and processing. An anonymous nursery provided samples of $P$. sylvestris that were declining from LBD and gave permission to destructively sample the palms. This species was selected because of the rapid decline of $P$. sylvestris in Florida, it was available from the grower, and it is the most commonly received species in plant diagnostic clinics. Three specimens were selected, with one exhibiting early symptoms (Fig. 1A), a second exhibiting moderate symptoms (Fig. 1B), and the third exhibiting late stage symptoms (Fig. 1C). Additionally, a specimen of S. palmetto with late stage symptoms (Fig. 2) was identified at Fort Lauderdale Research and Education Center, where permission was attained to destructively sample the palm. This specimen was also included in the study because the palm was accessible, S. palmetto is one of the more commonly infected (and sampled) palm species in Florida, and it is both an ornamental and native species, serving as an important species in the natural ecosystem and the landscaping industry. Early symptoms (ES), moderate symptoms (MS), and late symptoms (LS) are defined as $\leq 25 \%$ canopy discoloration, about $50 \%$ canopy discoloration, and $\geq 75 \%$ canopy discoloration, respectively. All specimens were cut down with a chainsaw at ground level and divided into segments that were approximately $15 \mathrm{~cm}$ long, demarcated with spray paint around the circumference, and labeled numerically. Each segment was divided into eight sections (resulting in eight samples per segment) and labeled alphabetically, creating a grid over the entire trunk length (Fig. 3). From each block on the grid, a single trunk sample was taken, allowing $1 \mathrm{~g}$ of tissue to be extracted. The single sample extracted from each block in the grid constitutes the removal of pseudobark and the insertion of the drill $13 \mathrm{~cm}$ into the pith, removing $1 \mathrm{~g}$ of this tissue. Based on eight samples per

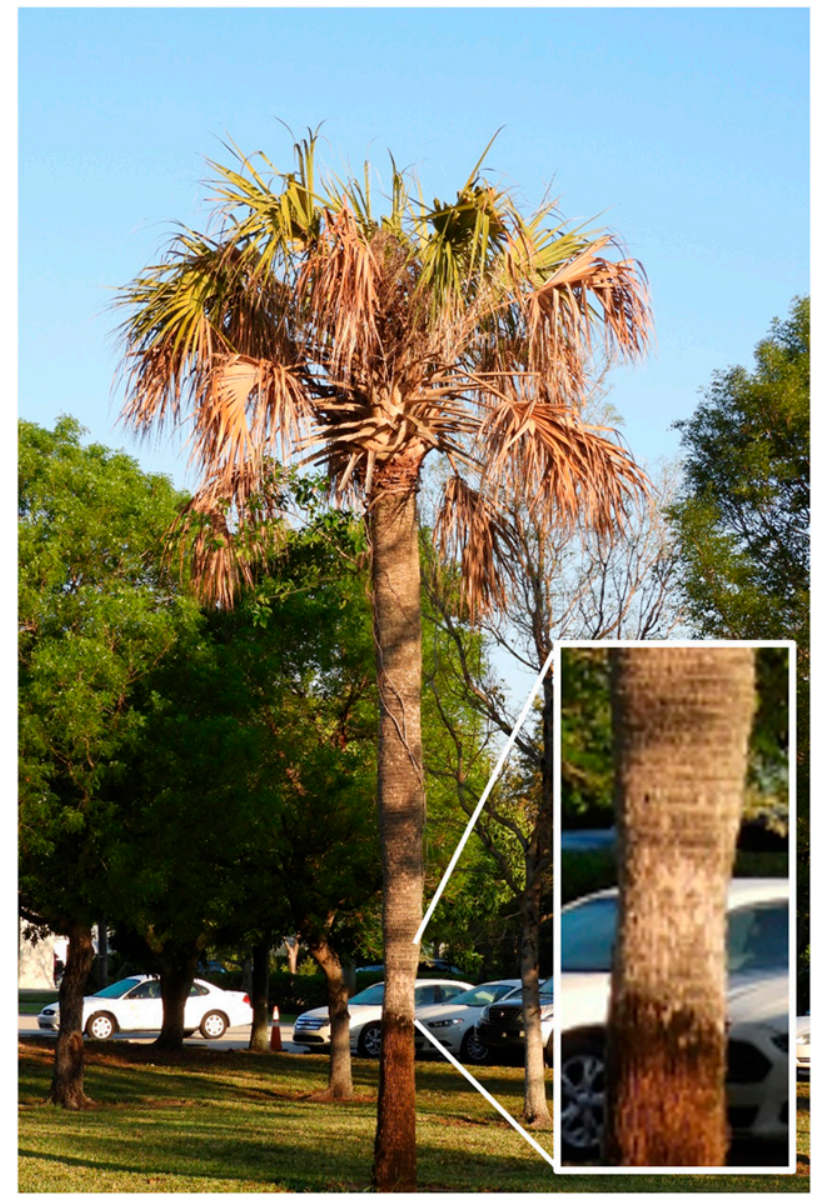

Fig. 2. Specimen of Sabal palmetto displaying late stage symptoms of lethal bronzing disease, used to map the distribution of the 16SrIV-D phytoplasma in the trunk; constriction magnified.

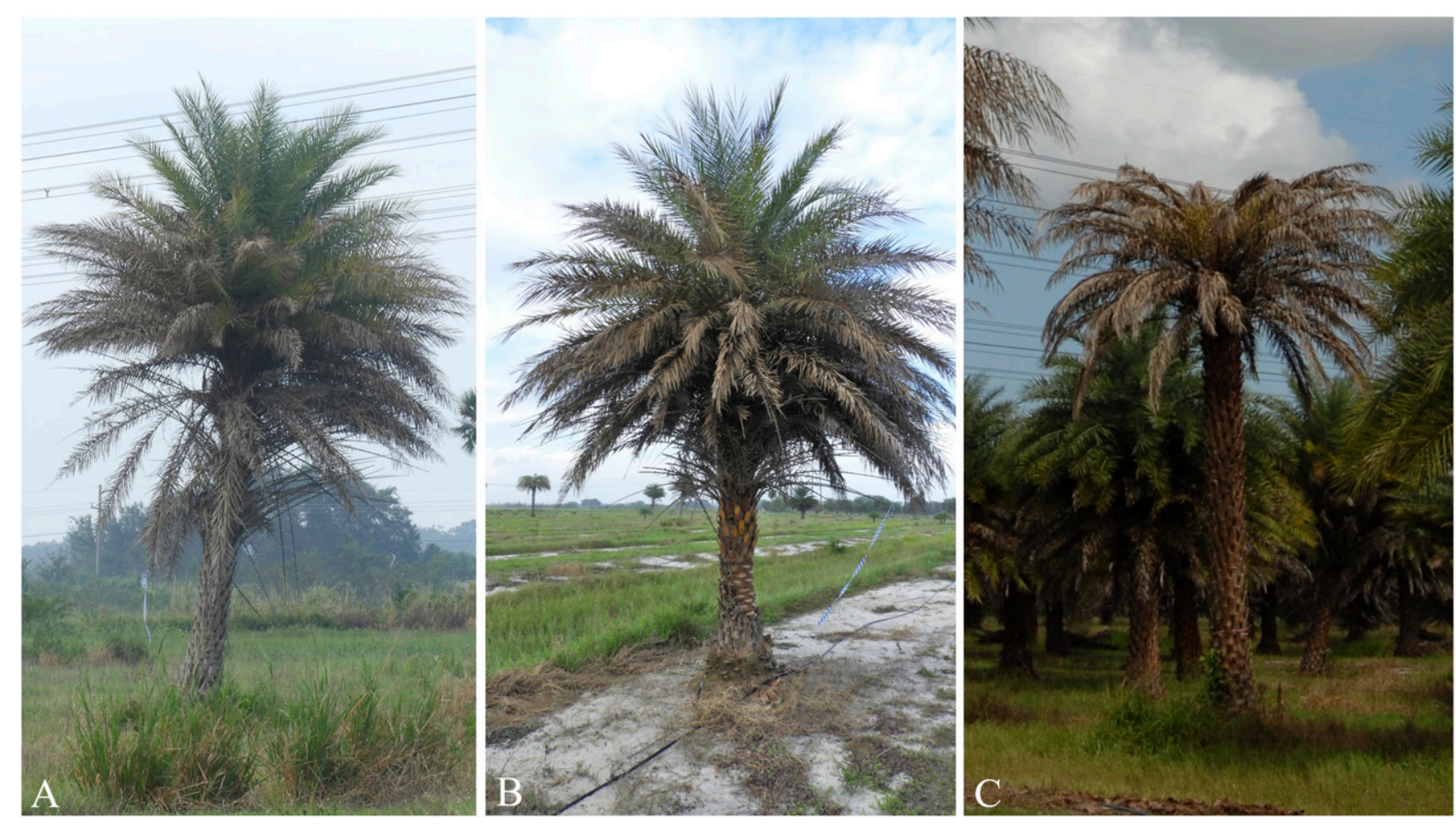

Fig. 1. Specimens of Phoenix sylvestris infected with the 16SrIV-D phytoplasma used to map the distribution throughout the trunk: A, early symptoms; B, moderate symptoms; and C, late symptoms of lethal bronzing disease. 

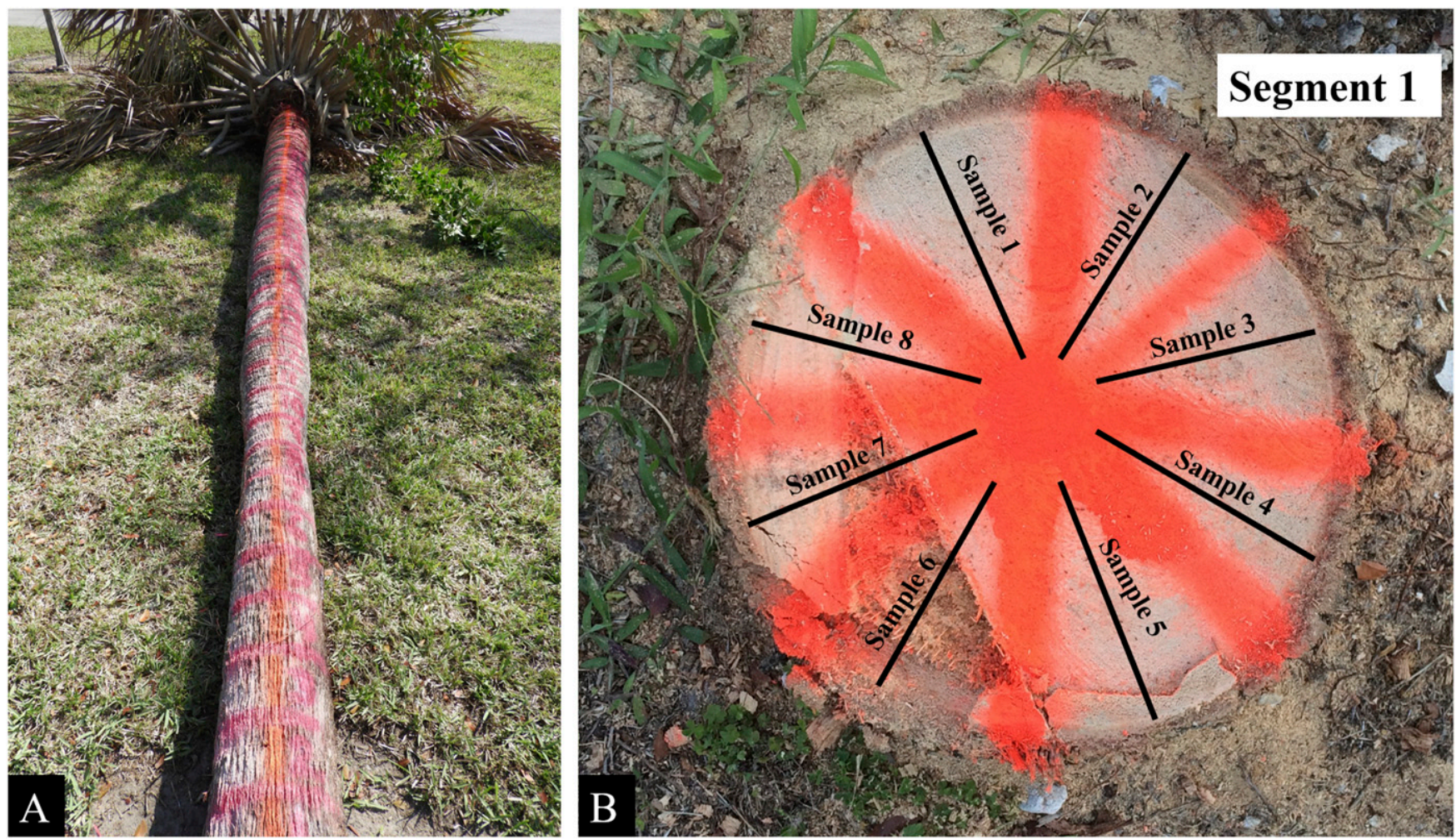

Fig. 3. A, Trunk of Sabal palmetto displaying grid pattern as an example for sampling all individuals. B, Cross section of S. palmetto trunk displaying sections present in each segment. Grid pattern and sampling regime was the same for Phoenix sylvestris; black lines represent single samples taken in each segment.

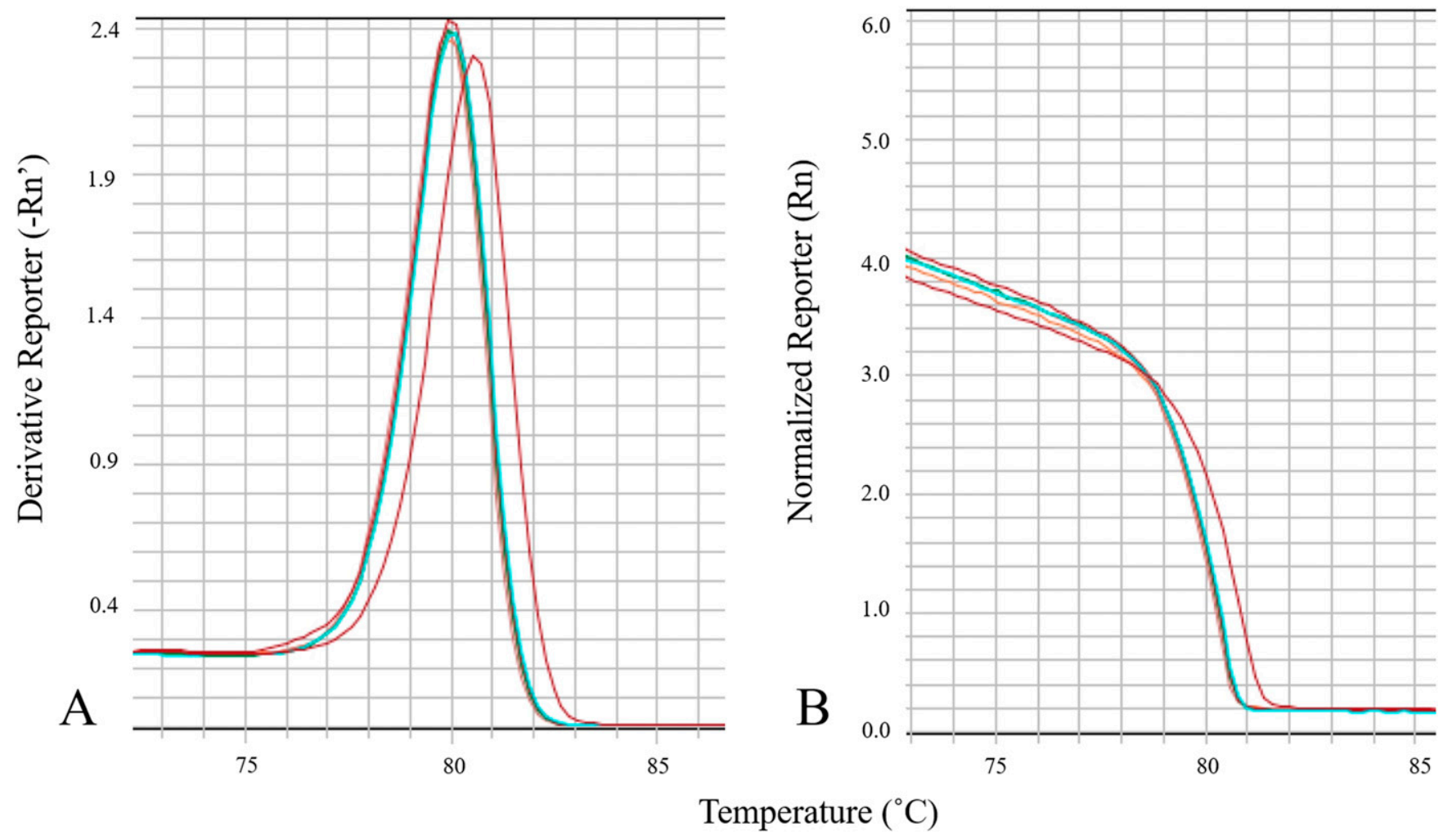

Fig. 4. Melt curve plots for isolates of the 16SrIV-D phytoplasma obtained from the four palms analyzed in this study for A, the derivative reporter and B, normalized reporter. Single line, 16SrIV-A positive control; clustered lines, samples and 16SrIV-D positive control. 
segment multiplied by the number of segments on the palm, the total number of samples taken per palm varied because they were different heights. Samples were immediately stored in a cooler and transported to the laboratory, where they were stored at $-80^{\circ} \mathrm{C}$ until processing. Total DNA was extracted according to the protocol outlined by Bahder et al. (2019a).

Subgroup identification. To classify the phytoplasma isolates obtained in this study, each palm was tested by real-time PCR followed by melt curve analysis as per Bahder et al. (2017). This approach was used to confirm the phytoplasma in the infected palms was 16 SrIV-D, not 16 SrIV-A. PCR was run under the same conditions used by Bahder et al. (2017). The primer set used PP16S-32 (forward) and PP16S-132 (reverse) (Bahder et al. 2017).

Quantitative PCR assay parameters and phytoplasma quantification. For quantifying phytoplasma titers throughout the palm trunk, quantitative PCR (qPCR) reactions were run with reactions comprised of $10 \mu \mathrm{l}$ of a master mix and $0.10 \mu \mathrm{M}$ of each primer and of the probe for a total reaction volume of $20 \mu$ l. Primers used were LY16S-LSF and -LSR and the probe LY16S (Córdova et al. 2014). Thermal cycling conditions were as follows: $95^{\circ} \mathrm{C}$ for $10 \mathrm{~min}, 35$ cycles of $95^{\circ} \mathrm{C}$ for $30 \mathrm{~s}, 60^{\circ} \mathrm{C}$ for $60 \mathrm{~s}$, and $72^{\circ} \mathrm{C}$ for 30 s Data were collected and analyzed in QuantStudio Real-Time PCR Software version 1.3. All reactions were run in triplicate.

Standard curve was generated with plasmid standards with inserts generated from the LY16S-LSF and -LSR primer set as per Bahder et al. (2018b). Plasmid standard log dilution used ranged from $10^{8}$ copies/ $\mu 1$ to $10^{3}$ copies/ $\mu 1$.

\section{Results}

Subgroup verification. All three $P$. sylvestris used in this study were shown to be infected with the 16SrIV-D phytoplasma because the melting curve matched that of the positive control of the 16SrIVD plasmid standard (Fig. 4) as well as yielding a melting temperature that fell within the range of the 16 SrIV-D phytoplasma (Table 1). The isolate from the infected $S$. palmetto was also confirmed as infected with the 16SrIV-D phytoplasma because of melt curve analysis (Fig. 4) and melting temperature product (Table 1).

Table 1. Melt curve analysis for verification of the 16SrIV-D phytoplasma in palms analyzed

\begin{tabular}{llc}
\hline Species & Symptoms & Melting temperature product \\
\hline Phoenix sylvestris & Early & 80.03 \\
P. sylvestris & Moderate & 79.93 \\
P. sylvestris & Late & 80.03 \\
Sabal palmetto & Late & 80.03 \\
16SrIV-D (+) control & n/a & 80.03 \\
16SrIV-A (+) control & n/a & 80.52 \\
Healthy (-) control & n/a & 60.91 \\
\hline
\end{tabular}

Quantification and distribution of the 16SrIV-D phytoplasma in $P$. sylvestris. In the $P$. sylvestris exhibiting ES, the phytoplasma titer was higher in the lower portion of the palm and dropped further up the trunk (Fig. 5). The highest level of phytoplasma detected on average was in segment 5 (about 580,000 copies/ $\mu$ l) (Fig. 5), approximately $75 \mathrm{~cm}$ from ground level. The phytoplasma level began to decrease after segment 8 (approximately $1.2 \mathrm{~m}$ from ground level) (Fig. $5)$ and yielded low levels $(<100,000$ copies $/ \mu l)$ of phytoplasma until the crown with the exception of segment 15 , where a slight increase in phytoplasma titer (about 200,000 copies/ $\mu$ l) was detected (Fig. 5). Every sample from each section within each segment yielded a positive reaction (Table 2). However, the same section did not always yield the highest level of phytoplasma along the entire length of the trunk. Conversely, the same section did not always yield the lowest level of phytoplasma along the length of the trunk (Table 2).

In the $P$. sylvestris exhibiting MS, the phytoplasma titer was higher in the lower portion of the palm, with peak amount occurring in segment 2 (approximately $30 \mathrm{~cm}$ above ground level) (Fig. 6). The highest level of phytoplasma detected on average in segment 2 was about 45,000 copies $/ \mu l$. The titer decreased moving up the trunk, then in

Table 2. Quantity and distribution of the 16SrIV-D phytoplasma along the length of trunk from a Phoenix sylvestris displaying early symptoms of lethal bronzing disease, with segment 1 being ground level

\begin{tabular}{|c|c|c|c|}
\hline Segment & $\begin{array}{l}\text { Average quantity } \\
(\text { copies/ } / \mu \mathrm{l})\end{array}$ & $\begin{array}{c}\text { Section with } \\
\text { highest quantity }\end{array}$ & $\begin{array}{c}\text { Section with lowest } \\
\text { quantity }\end{array}$ \\
\hline 1 & $172,367 \pm 6,525$ & A $(189,895 \pm 345)$ & $\mathrm{C}(130,612 \pm 455)$ \\
\hline 2 & $136,219 \pm 21,377$ & A $(201,473 \pm 289)$ & $\mathrm{G}(9,113 \pm 50,333)$ \\
\hline 3 & $396,125 \pm 54,022$ & $\mathrm{~B}(678,013 \pm 566)$ & $F(251,668 \pm 444)$ \\
\hline 4 & $538,573 \pm 48,053$ & $C(760,641 \pm 332)$ & A $(323,862 \pm 541)$ \\
\hline 5 & $572,291 \pm 49,751$ & B $(841,234 \pm 434)$ & $F(407,004 \pm 339)$ \\
\hline 6 & $367,713 \pm 40,201$ & B $(531,025 \pm 290)$ & $F(182,224 \pm 476)$ \\
\hline 7 & $358,974 \pm 44,644$ & $G(600,167 \pm 556)$ & A $(225,126 \pm 677)$ \\
\hline 8 & $481,944 \pm 72,761$ & $\mathrm{D}(760,347 \pm 444)$ & $\mathrm{F}(207,505 \pm 800)$ \\
\hline 9 & $186,786 \pm 52,093$ & $C(469,644 \pm 566)$ & $G(52,294 \pm 339)$ \\
\hline 10 & $37,307 \pm 15,117$ & $\mathrm{~A}(114,166 \pm 150)$ & $\mathrm{G}(2,593 \pm 99)$ \\
\hline 11 & $16,592 \pm 5,114$ & $\mathrm{C}(47,587 \pm 333)$ & $F(3,553 \pm 201)$ \\
\hline 12 & $40,532 \pm 10,154$ & $\mathrm{~F}(80,089 \pm 189)$ & $\mathrm{B}(3,320 \pm 56)$ \\
\hline 13 & $52,740 \pm 9,580$ & $F(101,839 \pm 133)$ & $\mathrm{H}(25,006 \pm 322)$ \\
\hline 14 & $57,629 \pm 3,804$ & $\mathrm{D}(73,775 \pm 209)$ & $\mathrm{G}(41,580 \pm 122)$ \\
\hline 15 & $201,785 \pm 82,050$ & $\mathrm{D}(581,568 \pm 444)$ & $\mathrm{H}(8,327 \pm 100)$ \\
\hline 16 & $6,670 \pm 1,814$ & $\mathrm{G}(17,235 \pm 232)$ & $\mathrm{H}(2,504 \pm 98)$ \\
\hline 17 & $4,924 \pm 455$ & $E(6,769 \pm 101)$ & $\mathrm{D}(3,417 \pm 155)$ \\
\hline 18 & $5,950 \pm 1,156$ & $\mathrm{E}(11,913 \pm 455)$ & $\mathrm{H}(2,749 \pm 59)$ \\
\hline 19 & $6,046 \pm 1,611$ & $\mathrm{E}(12,372 \pm 376)$ & A $(946 \pm 29)$ \\
\hline 20 & $16,208 \pm 3,436$ & $\mathrm{D}(35,651 \pm 409)$ & $\mathrm{G}(8,172 \pm 200)$ \\
\hline 21 & $20,093 \pm 4,532$ & $\mathrm{~F}(39,994 \pm 463)$ & $\mathrm{H}(8,612 \pm 199)$ \\
\hline 22 & $15,915 \pm 2,381$ & A $(28,157 \pm 151)$ & B $(7,761 \pm 269)$ \\
\hline 23 & $17,013 \pm 6,065$ & $G(58,604 \pm 126)$ & $\mathrm{H}(5,165 \pm 172)$ \\
\hline 24 & $7,760 \pm 947$ & $F(11,993 \pm 477)$ & $\mathrm{H}(4,044 \pm 166)$ \\
\hline
\end{tabular}

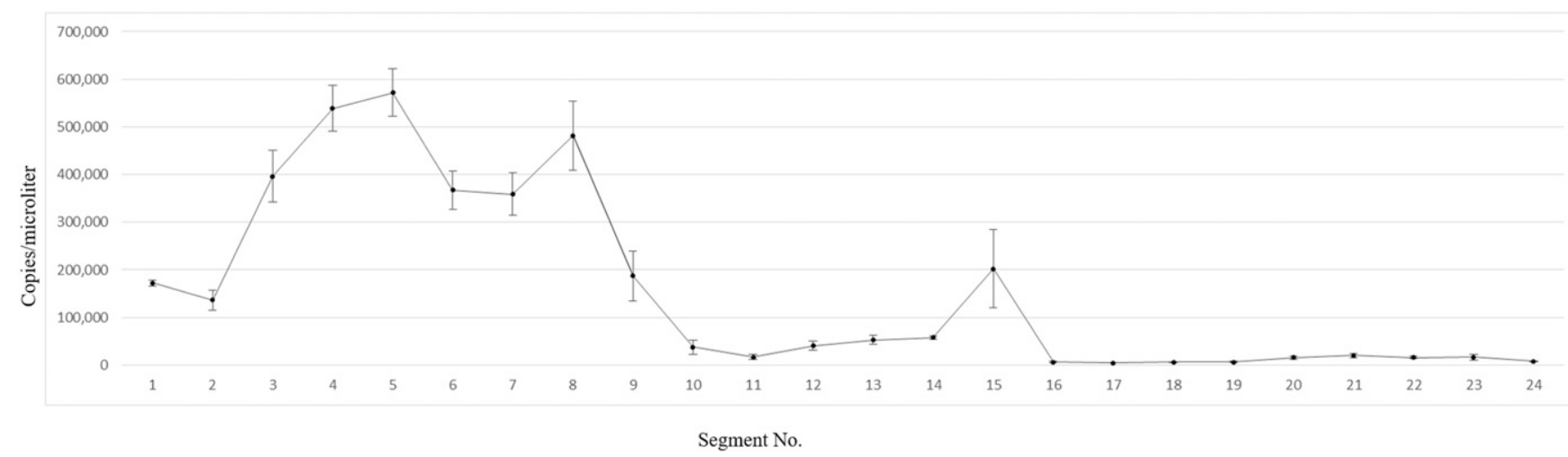

Fig. 5. 16SrIV-D phytoplasma titer throughout the trunk of a Phoenix sylvestris palm displaying early symptoms of lethal bronzing disease. 
segment 16 (approximately $2.4 \mathrm{~m}$ above ground level) it began increasing until reaching the crown (Fig. 6). Every sample from each section within each segment yielded a positive reaction (Table 3 ). However, the same section did not always yield the highest level of phytoplasma along the entire length of the trunk. Conversely, the same section did not always yield the lowest level of phytoplasma along the length of the trunk (Table 3 ).

In the $P$. sylvestris exhibiting LS, the phytoplasma titer was highest in segment 1 (approximately $15 \mathrm{~cm}$ from ground level), yielding on average 58,000 copies/ $\mu$ l. After segment 1 , the phytoplasma titer dropped substantially after segment 4 and began decreasing further to $<20,000$ copies/ $\mu 1$ for the remaining portion of the trunk (Fig. 7). Every sample from each section within each segment yielded a positive reaction (Table 4). However, the same section did not always yield the highest level of phytoplasma along the entire length of the trunk. Conversely, the same section did not always yield the lowest level of phytoplasma along the length of the trunk (Table 4). Similar to the ES palm, there was a slight increase after the midpoint of the trunk before decreasing again. The ES palm had overall the highest level of phytoplasma detected, whereas the MS had the second highest overall amount of phytoplasma and LS palm had the lowest amount among the $P$. sylvestris sampled. Regardless of symptoms, every reaction from every sample for all three palms yielded a positive result.

Quantification and distribution of the 16SrIV-D phytoplasma in S. palmetto. In the infected S. palmetto (LS), the highest levels of phytoplasma were detected in segment 4 (approximately $60 \mathrm{~cm}$ above ground level) and in segment 33 (approximately $5 \mathrm{~m}$ above ground level and directly below the crown) (Fig. 8). Over the length of the trunk, phytoplasma titers decreased slightly moving upward, then began increasing in titer around segment 31 (nearing the apical meristem) (Fig. 8). This overall trend was most similar to that seen in the MS P. sylvestris. For nearly the entire length of the trunk, the LS $S$. palmetto had on average twice the level of phytoplasmas as did the LS $P$. sylvestris. The variability in phytoplasma titer around the circumference was much higher in S. palmetto than in P. sylvestris (Fig. 8 , Table 5). The section with the highest level of phytoplasma per segment was not the same along the length of the entire trunk. Conversely, the section with the lowest level of phytoplasma per segment was not the same along the length of the trunk (Table 5).

\section{Discussion}

This study provides useful data that are directly usable by stakeholders wanting to sample palms and test for the presence of phytoplasma. The results indicate that in $P$. sylvestris, there is a general trend of higher levels of phytoplasmas lower in the trunk at all stages of decline and that there are regions with substantially higher levels of phytoplasmas relative to other sites at the same height on the palm. Additionally, at all stages of decline in $P$. sylvestris, as well as in $S$. palmetto exhibiting LS, every sample taken yielded a positive qPCR result.

The trend of higher levels of phytoplasmas being present in the lower portions of the palm trunk are consistent with previous, anecdotal evidence (N. A. Harrison, personal communication) and studies that have documented 16SrIV phytoplasmas in different plant tissues (Córdova et al. 2014; Oropeza et al. 2011). Furthermore, previous studies have hypothesized that phytoplasmas move from source tissue into sink tissue (Parthasarathy 1974; Zimmerman 1979) via phloem through passive flow. Recently, it was documented that the 16SrIV-D phytoplasma is generally absent in leaf tissue of symptomatic palms with the exception of the spear leaf (Bahder et al. 2019b). Given that the mature leaves are the site of inoculation from the insect vector, the absence of the phytoplasma in these leaves, and the trend of higher titers in the lower portion of the trunk, it appears that these data support the passive movement of the phytoplasma from the inoculation site (source) to the roots (sink), where the phytoplasma then begins to replicate and increase in concentration. The presence of regions with greater levels of phytoplasma relative to other sites at the same height could indicate the original sieve elements invaded by the phytoplasma after inoculation. The fact that these hotspots are not always in the same section reflects the internal morphology of palm phloem tissue where vascular tubes do not run linear along the trunk from top to bottom but rather twist in a helixlike fashion (Zimmerman and Tomlinson 1974). Interestingly, in the S. palmetto there was a consistent drop in phytoplasma titer in all sections at segment 8 . This uniform drop in phytoplasma occurred at a constriction in the trunk. These constrictions commonly occur in $S$. palmetto as a result of drought stress and reduce vascular tissue. This reduction of vascular tissue appears to have resulted in a noticeable difference in phytoplasma titer because there was less phloem for

Table 3. Quantity and distribution of the 16SrIV-D phytoplasma along the length of trunk from a Phoenix sylvestris displaying moderate symptoms of lethal bronzing disease, with segment 1 being ground level

\begin{tabular}{|c|c|c|c|}
\hline Segment & $\begin{array}{l}\text { Average quantity } \\
(\text { copies/ } / \mu \mathrm{l})\end{array}$ & $\begin{array}{l}\text { Section with highest } \\
\text { quantity }\end{array}$ & $\begin{array}{c}\text { Section with lowest } \\
\text { quantity }\end{array}$ \\
\hline 1 & $40,062 \pm 7,820$ & A $(71,352 \pm 332)$ & $\mathrm{E}(10,241 \pm 200)$ \\
\hline 2 & $50,383 \pm 7,674$ & A $(91,771 \pm 108)$ & $\mathrm{G}(29,816 \pm 234)$ \\
\hline 3 & $44,301 \pm 7,695$ & $\mathrm{D}(75,582 \pm 400)$ & $\mathrm{F}(18,329 \pm 103)$ \\
\hline 4 & $28,506 \pm 7,617$ & $\mathrm{H}(79,755 \pm 122)$ & $\mathrm{C}(9,877 \pm 188$ \\
\hline 5 & $44,551 \pm 7,254$ & $\mathrm{~A}(70,582 \pm 89)$ & $\mathrm{D}(9,383 \pm 109)$ \\
\hline 6 & $30,097 \pm 7,498$ & $\mathrm{H}(68,242 \pm 101)$ & $\mathrm{B}(10,113 \pm 67)$ \\
\hline 7 & $26,802 \pm 4,787$ & $\mathrm{H}(54,430 \pm 133)$ & $F(9,970 \pm 66)$ \\
\hline 8 & $25,769 \pm 2,896$ & D $(40,937 \pm 144)$ & B $(13,637 \pm 29)$ \\
\hline 9 & $24,366 \pm 8,966$ & $\mathrm{G}(78,861 \pm 100)$ & B $(7,143 \pm 130)$ \\
\hline 10 & $18,561 \pm 6,098$ & B $(59,298 \pm 129)$ & $\mathrm{C}(4,020 \pm 103)$ \\
\hline 11 & $24,529 \pm 5,332$ & $\mathrm{G}(45,320 \pm 80)$ & $\mathrm{E}(8,517 \pm 103)$ \\
\hline 12 & $13,086 \pm 4,606$ & A $(44,004 \pm 99)$ & $\mathrm{E}(4,554 \pm 134)$ \\
\hline 13 & $6,436 \pm 1,532$ & $\mathrm{G}(16,597 \pm 201)$ & $\mathrm{C}(2,950 \pm 97)$ \\
\hline 14 & $4,772 \pm 1,160$ & B $(10,661 \pm 200)$ & $C(1,566 \pm 106)$ \\
\hline 15 & $6,197 \pm 2,733$ & A $(11,188 \pm 176)$ & $\mathrm{C}(3,478 \pm 192)$ \\
\hline 16 & $21,223 \pm 6,644$ & B $(63,037 \pm 222)$ & $\mathrm{E}(6,018 \pm 128)$ \\
\hline 17 & $22,288 \pm 4,814$ & B $(40,971 \pm 302)$ & $\mathrm{C}(7,831 \pm 298)$ \\
\hline 18 & $20,791 \pm 3,867$ & $\mathrm{~A}(45,261 \pm 234)$ & $\mathrm{E}(9,521 \pm 251)$ \\
\hline 19 & $30,963 \pm 4,705$ & $\mathrm{~A}(53,139 \pm 304)$ & B $(15,681 \pm 222)$ \\
\hline
\end{tabular}

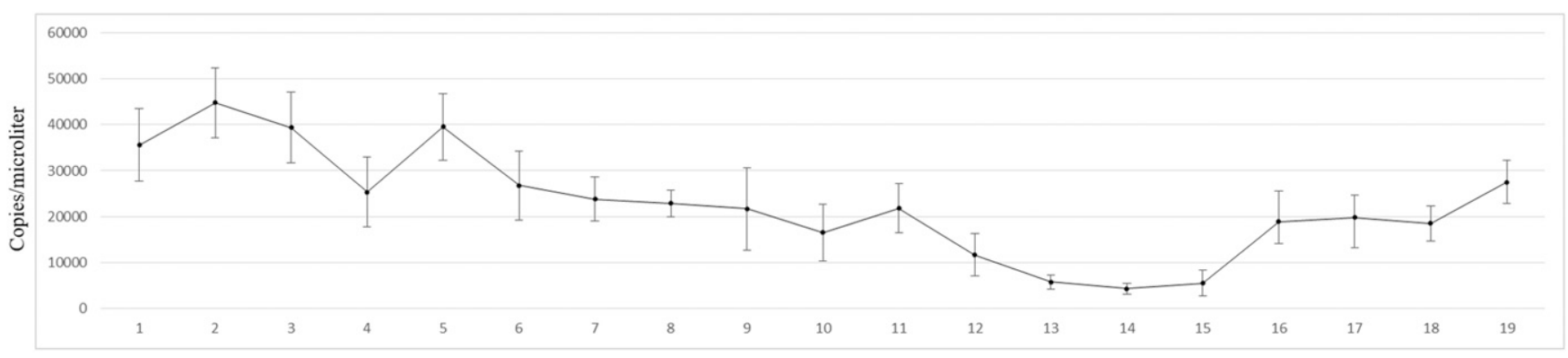

Segment No.

Fig. 6. 16SrIV-D phytoplasma titer throughout the trunk of a Phoenix sylvestris palm displaying moderate symptoms of lethal bronzing disease. 
the phytoplasma to persist in. Despite having lower levels of phytoplasma at the constriction, there was still enough to detect in each section. The S. palmetto was exhibiting LS, and it is unknown what effect sampling at a constriction will have on amplification success in palms with ES or those in the latent period. Therefore, it is advisable for stakeholders to avoid sampling at constriction sites in order to reduce the possibility of false negatives in the event the palm does not have a fully systemic infection. No constrictions were observed in the $P$. sylvestris specimens, meaning drops in phytoplasma at various spots in these samples are probably caused by natural variation in distribution.

The uneven distribution of phytoplasmas in plant tissue is well documented (Christensen et al. 2004; Lherminier et al. 1994; Oropeza et al. 2011; Siddique et al. 1998), which is why historically stakeholders have been instructed to take multiple samples at different heights when testing a palm for the 16SrIV-D phytoplasma. Based on this study, it is evident that once symptoms appear in the palm, the phytoplasma is fully systemic, and thus only a single sample is needed to yield a positive reaction. Although future works should focus on other palm species, as resources become available, to verify that this trend is consistent, the data derived from $P$. sylvestris are crucial because this species has been documented as the most commonly sampled and infected palm species in Florida (Bahder et al. 2019a). Although this trend is likely to be the same in other palms, it is not likely to be the same in infected palms in the latent stage before symptom development. Although the 16SrIV-D is detectable in asymptomatic palms (Bahder et al. 2018a; Vázquez-Euán et al. 2011), it is not possible to tell how long the palm has been infected and thus how far along the infection is. At this stage, the phytoplasma may or may not be fully systemic, increasing the likelihood of a false negative if a single sample is taken. Based on this uncertainty, if asymptomatic palms are being sampled, it is recommended that multiple samples be taken at different locations to accommodate the more sporadic distribution that is expected in the earlier stages of the disease cycle.

Although this study provides some insight into the biology of the phytoplasma within infected palms, it mainly provides a dataset that is directly usable by stakeholders. These findings will reduce the time

Table 4. Quantity and distribution of the 16SrIV-D phytoplasma along the length of trunk from a Phoenix sylvestris displaying late symptoms of lethal bronzing disease, with segment 1 being ground level

\begin{tabular}{|c|c|c|c|}
\hline Segment & $\begin{array}{l}\text { Average quantity } \\
(\text { copies } / \mu \mathrm{l})\end{array}$ & $\begin{array}{l}\text { Section with highest } \\
\text { quantity }\end{array}$ & $\begin{array}{c}\text { Section with lowest } \\
\text { quantity }\end{array}$ \\
\hline 1 & $56,731 \pm 8,465$ & $F(91,511 \pm 136)$ & $\mathrm{G}(17,758 \pm 355)$ \\
\hline 2 & $21,498 \pm 3,012$ & $\mathrm{D}(32,979 \pm 200)$ & $\mathrm{H}(10,937 \pm 103)$ \\
\hline 3 & $24,229 \pm 4,445$ & $\mathrm{D}(51,403 \pm 198)$ & $\mathrm{G}(6,825 \pm 89)$ \\
\hline 4 & $27,305 \pm 6,946$ & $\mathrm{D}(64,986 \pm 144)$ & $H(6,102 \pm 123)$ \\
\hline 5 & $14,121 \pm 2,711$ & $\mathrm{~F}(29,379 \pm 153)$ & B $(8,332 \pm 196)$ \\
\hline 6 & $12,696 \pm 5,383$ & $\mathrm{C}(49,889 \pm 122)$ & $\mathrm{D}(4,953 \pm 139)$ \\
\hline 7 & $11,784 \pm 2,724$ & $\mathrm{C}(25,446 \pm 204)$ & $\mathrm{G}(1,201 \pm 166)$ \\
\hline 8 & $9,101 \pm 2,203$ & $\mathrm{~F}(18,001 \pm 100)$ & $\mathrm{C}(1,215 \pm 99)$ \\
\hline 9 & $14,156 \pm 4,083$ & $\mathrm{~F}(33,367 \pm 168)$ & $\mathrm{G}(1,158 \pm 77)$ \\
\hline 10 & $14,945 \pm 4,113$ & $\mathrm{C}(31,368 \pm 111)$ & $\mathrm{G}(3,499 \pm 199)$ \\
\hline 11 & $9,229 \pm 2,797$ & $\mathrm{C}(25,976 \pm 133)$ & $\mathrm{G}(2,576 \pm 200)$ \\
\hline 12 & $9,782 \pm 3,126$ & $\mathrm{~F}(20,284 \pm 145)$ & $\mathrm{H}(1,212 \pm 98)$ \\
\hline 13 & $10,948 \pm 2,739$ & $\mathrm{E}(21,229 \pm 149)$ & $\mathrm{G}(1,413 \pm 56)$ \\
\hline 14 & $8,712 \pm 2,862$ & $\mathrm{D}(25,599 \pm 133)$ & $\mathrm{H}(1,639 \pm 177)$ \\
\hline 15 & $9,626 \pm 3,089$ & $\mathrm{C}(28,948 \pm 100)$ & $\mathrm{G}(2,290 \pm 95)$ \\
\hline
\end{tabular}

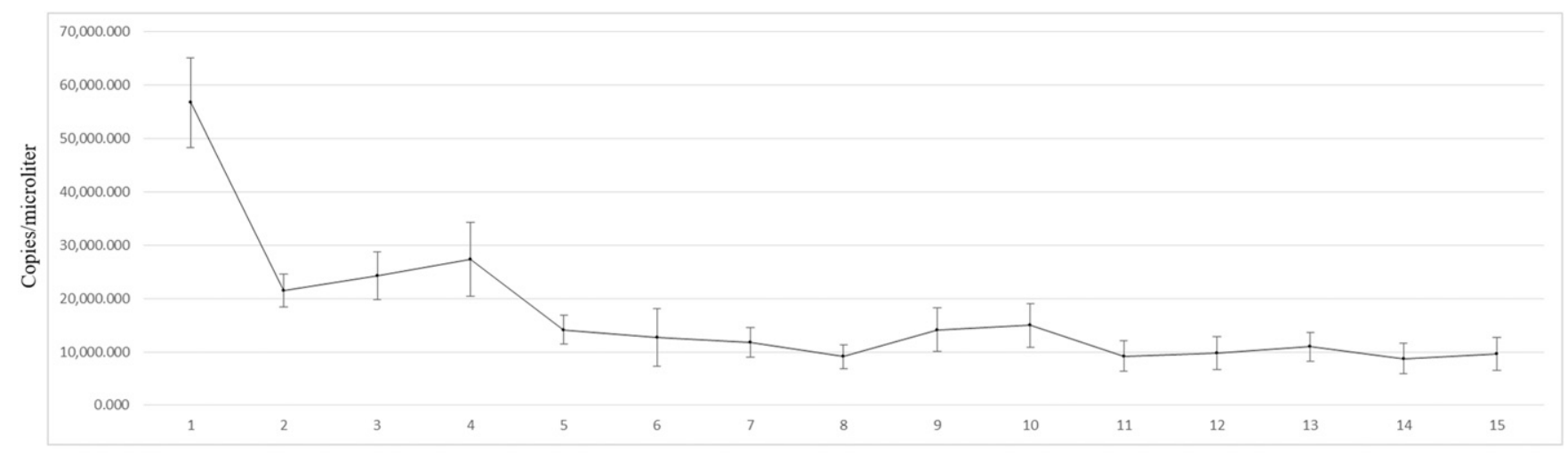

Segment No.

Fig. 7. 16SrlV-D phytoplasma titer throughout the trunk of a Phoenix sylvestris palm displaying late symptoms of lethal bronzing disease.

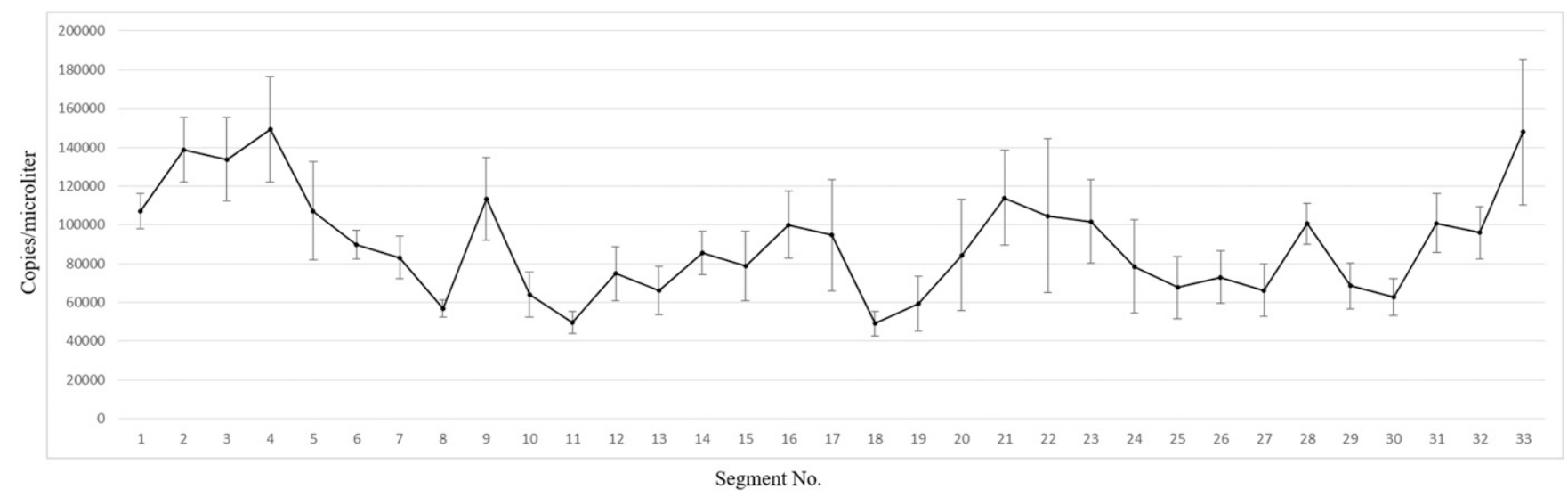

Fig. 8. 16SrIV-D phytoplasma titer throughout the trunk of a Sabal palmetto palm displaying late symptoms of lethal bronzing disease. 
Table 5. Quantity and distribution of the 16SrIV-D phytoplasma along the length of trunk from a Sabal palmetto displaying late symptoms of lethal bronzing disease, with segment 1 being ground level

\begin{tabular}{|c|c|c|c|}
\hline Segment & $\begin{array}{l}\text { Average quantity } \\
\quad(\text { copies/ } / \mu \mathrm{l})\end{array}$ & $\begin{array}{l}\text { Section with highest } \\
\text { quantity }\end{array}$ & $\begin{array}{c}\text { Section with lowest } \\
\text { quantity }\end{array}$ \\
\hline 1 & $107,042 \pm 9,096$ & B $(170,124 \pm 143)$ & $\mathrm{H}(97,846 \pm 121)$ \\
\hline 2 & $138,617 \pm 16,626$ & D $(205,397 \pm 196)$ & $\mathrm{F}(75,589 \pm 188)$ \\
\hline 3 & $133,862 \pm 21,626$ & $\mathrm{C}(265,868 \pm 131)$ & $\mathrm{G}(85,367 \pm 111)$ \\
\hline 4 & $149,346 \pm 27,239$ & $F(322,708 \pm 200)$ & $\mathrm{H}(85,210 \pm 196)$ \\
\hline 5 & $107,222 \pm 25,344$ & $\mathrm{H}(281,234 \pm 134)$ & $\mathrm{E}(55,517 \pm 122)$ \\
\hline 6 & $89,995 \pm 7,389$ & $\mathrm{G}(126,055 \pm 190)$ & $E(62,363 \pm 101)$ \\
\hline 7 & $83,157 \pm 10,839$ & A $(153,956 \pm 122)$ & $\mathrm{H}(52,403 \pm 103)$ \\
\hline 8 & $56,767 \pm 4,560$ & $\mathrm{C}(83,191 \pm 129)$ & $\mathrm{H}(42,896 \pm 190)$ \\
\hline 9 & $113,339 \pm 21,380$ & $\mathrm{D}(258,327 \pm 166)$ & B $(72,673 \pm 98)$ \\
\hline 10 & $64,077 \pm 11,602$ & $\mathrm{C}(132,541 \pm 123)$ & $\mathrm{H}(33,944 \pm 200)$ \\
\hline 11 & $49,625 \pm 5,806$ & $\mathrm{D}(79,502 \pm 107)$ & $\mathrm{F}(28,944 \pm 200)$ \\
\hline 12 & $74,807 \pm 13,754$ & $F(132,616 \pm 133)$ & $\mathrm{B}(41,200 \pm 102)$ \\
\hline 13 & $66,177 \pm 12,435$ & $\mathrm{C}(133,711 \pm 111)$ & B $(25,901 \pm 122)$ \\
\hline 14 & $85,409 \pm 11,134$ & $\mathrm{E}(140,495 \pm 100)$ & $\mathrm{G}(51,808 \pm 79)$ \\
\hline 15 & $78,663 \pm 17,997$ & B $(162,775 \pm 89)$ & $\mathrm{C}(35,196 \pm 97)$ \\
\hline 16 & $100,031 \pm 17,281$ & $\mathrm{~F}(220,376 \pm 88)$ & $\mathrm{C}(60,400 \pm 91)$ \\
\hline 17 & $94,649 \pm 28,634$ & $\mathrm{H}(284,013 \pm 99)$ & $\mathrm{C}(22,709 \pm 70)$ \\
\hline 18 & $49,065 \pm 6,366$ & $\mathrm{D}(84,634 \pm 100)$ & $\mathrm{H}(36,126 \pm 95)$ \\
\hline 19 & $59,220 \pm 14,142$ & $\mathrm{~A}(136,759 \pm 101)$ & $F(35,369 \pm 92)$ \\
\hline 20 & $84,330 \pm 28,725$ & $F(247,304 \pm 122)$ & $\mathrm{C}(18,907 \pm 201)$ \\
\hline 21 & $113,964 \pm 24,491$ & A $(237,759 \pm 129)$ & B $(42,596 \pm 102)$ \\
\hline 22 & $104,630 \pm 39,729$ & $\mathrm{G}(126,445 \pm 112)$ & $\mathrm{C}(37,867 \pm 202)$ \\
\hline 23 & $101,647 \pm 21,489$ & $G(220,043 \pm 198)$ & $\mathrm{C}(34,282 \pm 79)$ \\
\hline 24 & $78,553 \pm 23,943$ & A $(242,328 \pm 99)$ & $\mathrm{E}(34,602 \pm 90)$ \\
\hline 25 & $67,666 \pm 16,188$ & $\mathrm{H}(159,063 \pm 117)$ & $\mathrm{E}(36,413 \pm 100)$ \\
\hline 26 & $73,076 \pm 13,639$ & $\mathrm{D}(147,861 \pm 125)$ & $\mathrm{C}(35,345 \pm 199)$ \\
\hline 27 & $66,295 \pm 13,357$ & $\mathrm{~A}(122,241 \pm 165)$ & $\mathrm{G}(41,879 \pm 110)$ \\
\hline 28 & $100,619 \pm 10,606$ & $\mathrm{D}(147,869 \pm 77)$ & B $(52,246 \pm 86)$ \\
\hline 29 & $68,542 \pm 11,701$ & $\mathrm{E}(131,094 \pm 88)$ & B $(40,496 \pm 92)$ \\
\hline 30 & $62,624 \pm 9,514$ & $G(105,266 \pm 100)$ & $\mathrm{C}(30,468 \pm 102)$ \\
\hline 31 & $100,874 \pm 15,270$ & $\mathrm{D}(212,556 \pm 80)$ & A $(79,898 \pm 72)$ \\
\hline 32 & $96,017 \pm 13,540$ & $\mathrm{E}(165,641 \pm 144)$ & $\mathrm{D}(61,970 \pm 133)$ \\
\hline 33 & $147,834 \pm 37,465$ & $\mathrm{~F}(306,784 \pm 181)$ & B $(39,745 \pm 100)$ \\
\hline
\end{tabular}

spent sampling by nursery and landscape personnel by allowing them to take a single sample from a symptomatic palm rather than three to five. Finally, based on these results, if a palm is symptomatic, it is advised that samples be taken from lower portions of the trunk, approximately $\leq 1 \mathrm{~m}$, to attain samples with higher levels of phytoplasma, allowing clearer diagnostic results.

\section{Literature Cited}

Bahder, B. W., and Helmick, E. E. 2018. Sampling palms for lethal yellowing and Texas Phoenix palm decline phytoplasmas. UF/IFAS Extension document ENY-990.

Bahder, B. W., and Helmick, E. E. 2019. Lethal bronzing disease (LBD). UF/IFAS Extension document PP243.

Bahder, B. W., Helmick, E. E., Chakrabati, S., Osorio, S., Soto, N., Chouvenc, T., and Harrison, N. A. 2018a. Disease progression of a lethal decline caused by the 16SrIV-D phytoplasma in Florida palms. Plant Pathol. 67:1821-1828.

Bahder, B. W., Helmick, E. E., and Harrison, N. A. 2017. Detecting and differentiating phytoplasmas belonging to subgroups 16SrIV-A and 16SrIV-D associated with lethal declines of palms in Florida using qPCR and highresolution melt analysis (HRMA). Plant Dis. 101:1449-1454.

Bahder, B. W., Helmick, E. E., Mou, D., Harrison, N. A., and Davis, R. 2018b. Digital PCR technology for detection of palm-infecting phytoplasmas belonging to group 16SrIV that occur in Florida. Plant Dis. 102:1008-1014.

Bahder, B. W., Soto, N., Helmick, E. E., Dey, K., Komondy, L., Humphries, A. R., Mou, D., Bailey, R., Ascunce, M., and Goss, E. M. 2019a. A survey of declining palms (Arecaceae) for the 16SrIV-D phytoplasma for evaluating distribution and host range in Florida. Plant Dis. 103:2512-2519.

Bahder, B. W., Soto, N., Komondy, L., Mou, D., Humphries, A. R., and Helmick, E. E. 2019b. Detection and quantification of the 16SrIV-D phytoplasma in leaf tissue of common ornamental palm species in Florida using qPCR and dPCR. Plant Dis. 103:1918-1922.

Christensen, N. M., Nicolaisen, M., Hansen, M., and Schulz, A. 2004. Distribution of phytoplasma in infected plants as revealed by real-time PCR and bioimaging. Mol. Plant-Microbe Interact. 17:1175-1184.

Córdova, I., Oropeza, C., Puch-Hau, C., Harrison, N., Collí-Rodríguez, A. Narvaez, M., Nic-Matos, G., Reyes, C., and Sáenz, L. 2014. A real-time PCR assay for detection of coconut lethal yellowing phytoplasmas of group 16SrIV subgroups A, D, and E found in the Americas. J. Plant Pathol. 96: 343-352.

Dey, K. K., Jeyaprakash, A., Hansen, J., Jones, D., Smith, T., Davison, D. Srivastava, P., Bahder, B., Li, C., and Sun, X. 2018. First report of the 16SrIV-D phytoplasma associated with decline of a Bismarck palm (Bismarckia nobilis). Plant Health Prog. 19:128.

Harrison, N. A., Bourne, C. M., Cox, R. L., Tsai, J. H., and Richardson, P. A. 1992. DNA probes for detection of mycoplasmalike organisms associated with lethal yellowing disease of palms in Florida. Phytopathology 82:216-224.

Harrison, N. A., Helmick, E. E., and Elliott, M. L. 2008. Lethal yellowing-type diseases of palms associated with phytoplasma newly identified in Florida, USA. Ann. Appl. Biol. 153:85-94.

Harrison, N. A., Helmick, E. E., and Elliott, M. L. 2009. First report of a phytoplasma-associated lethal decline of Sabal palmetto in Florida, USA. Plant Pathol. 58:792.

Harrison, N. A., Womack, M., and Carpio, M. L. 2002. Detection and characterization of a lethal yellowing (16SrIV) group phytoplasma in Canary Island date palms affected by lethal decline in Texas. Plant Dis. 86: 676-681.

Jeyaprakash, A., Sutton, B. D., Halbert, S. E., and Schubert, T. S. 2011. First report of a 16SrIV-D phytoplasma associated with Texas Phoenix palm decline on pigmy date palm (Phoenix roebelenii) in Florida. Plant Dis. 95:1475.

Khachatryan, H. and Hodges, A. W. 2014. Florida nursery crops and landscaping industry economic impacts, situation, and outlook. UF/IFAS Extension document FE946.

Lherminier, J., Courtois, M., and Caudwell, A. 1994. Determination of the distribution and multiplication sites of Flavescence dorée mycoplasma-like organisms in the host plant Vicia faba by ELISA and immunocytochemistry. Physiol. Mol. Plant Pathol. 45:125-138.

Oropeza, C., Cordova, I., Chumba, A., Narváez, M., Sáenz, L., Ashburner, R., and Harrison, N. A. 2011. Phytoplasma distribution in coconut palms affected by lethal yellowing disease. Ann. Appl. Biol. 159:109-117.

Parthasarathy, M. V. 1974. Mycoplasma-like organisms associated with lethal yellowing diseases of palms. Phytopathology 64:667-674.

Siddique, A., Guthrie, J., Walsh, K., White, D., and Scott, P. 1998. Histopathology and within-plant distribution of the phytoplasma associated with Australian papaya dieback. Plant Dis. 82:1112-1120.

Singh, R., and Ferguson, M. H. 2017. First report of a 'Candidatus Phytoplasma palmae'-related subgroup 16SrIV-D phytoplasma on Trachycarpus fortunei. Australas. Plant Dis. Notes 12:59.

Vázquez-Euán, R., Harrison, N., Narvaez, M., and Oropeza, C. 2011. Occurrence of a 16SrIV group phytoplasma not previously associated with palm species in Yucatan, Mexico. Plant Dis. 95:256-262.

Zimmerman, M. 1979. Mycoplasma diseases and long distance transport in plants. Chih wu pao hu hsueh hui hui kan. Plant Prot. Bull. 21(1):37-43.

Zimmerman, M. H., and Tomlinson, P. B. 1974. Vascular patterns in palm stems: variations of the Rhapis principle. J. Arnold Arbor. 55:402-424. 